\title{
Damage Constitutive Model of Microcrack Rock under Tension
}

\author{
Huiya Niu, ${ }^{1,2}$ Xingyu Zhang, ${ }^{1,2}$ Zhigang Tao $\mathbb{D}^{1}{ }^{1}$ and Manchao He $\mathrm{He}^{1,2}$ \\ ${ }^{1}$ State Key Laboratory of Geomechanics \& Deep Underground Engineering, China University of Mining \& Technology, \\ No. 16 Qinghua East Road, Haidian District, Beijing 100083, China \\ ${ }^{2}$ School of Mechanics and Civil Engineering, China University of Mining \& Technology, Ding No. 11 Xueyuan Road, \\ Haidian District, Beijing 100083, China
}

Correspondence should be addressed to Zhigang Tao; taozhigang@cumtb.edu.cn

Received 25 August 2020; Revised 22 October 2020; Accepted 26 October 2020; Published 19 November 2020

Academic Editor: Valeria Vignali

Copyright $\odot 2020$ Huiya Niu et al. This is an open access article distributed under the Creative Commons Attribution License, which permits unrestricted use, distribution, and reproduction in any medium, provided the original work is properly cited.

To investigate the tensile properties of brittle rock with microdamage, an indirect tensile test was conducted. High-speed image acquisition and acoustic emission (AE) were applied to record the process. After the tests, the images were analysed using the digital image correlation (DIC) method to obtain the stress and strain development of the rock under tension. The damage constitutive model was also developed in this study. Based on known and assumed statistical distributions for microcracks and the theory of fracture and statistical damage, the mechanical properties and failure mechanisms of brittle rock under tension were analysed. The basic statistical parameters of the main cracks in the elements were described, and the damage variable was defined to develop the effective modulus. A constitutive model for microdamage brittle rock-like materials was established based on the effective modulus. Additionally, to describe the crack propagation, a random-direction crack under tension was analysed to calculate the crack-tip stress intensity factor. After applying the basic parameters of the sandstone to the analytical model, the results showed that the analytical model agreed with the experimental results.

\section{Introduction}

As a natural solid material, generally composed of various mineral grains, cement, and pores, rock contains natural defects such as cracks and joints that are discontinuous, nonuniform, nonlinear, and anisotropic. Rock deformation and destruction occurs via defect initiation, expansion, interaction, and penetration [1-3]. Various methods have been applied to research rock properties, such as digital methods $[4,5]$, model developing [6-9], and experiments [10-17]. Current research on rock damage mechanics focuses on how to use a simple model to describe complex rock mechanics properties and then captures the influence of various different-scale crack interactions on the macroscopic mechanical behaviour of rocks [18-21].

The introduction of the damage mechanics theory to constitutive modelling of rock is a significant research direction. There are two research methods for the damage mechanics of rock: macroscopic analysis and mesoscopic analysis. Macroscopic analysis is based on continuum mechanics and aims to study the macroscopic behaviours of rock. The mesoscopic method is used to study the macroscopic mechanical behaviour caused by the generation and development of microcracks in rock. For materials with natural defects, such as rock, damage and its generation and development are microscopic phenomena, but the influence will result in macroscopic mechanical behaviours [22-25]. Mesoanalysis studies single defects on the mesoscale, and a statistical method is applied to describe the mesodefects and induce the larger damage field and damage evolution law of materials [26]. The range of crack length is 0.01 to $1.0 \mathrm{~mm}$. These microcracks are numerous, and the distribution is uneven. They can be described with statistical distributions [27]. In addition to the geometry and distribution of microcracks, the distribution of the element strength was also described by statistics, which uses statistical strength theory. Various element strength distributions have been considered, such as the random distribution [28], Weibull distribution [29, 30], power distribution, normal distribution [31], and lognormal distribution [32]. For element strength criterion, Drucker-Prager (D-P) criterion [33, 34], Mohr-Coulomb (M-C) criterion [27, 35], Hoek-Brown 
criterion [36, 37], and Lade-Duncan failure criterion [38] have been applied to predict mechanical characteristics of the rock element. When the load on the rock increases, microcracks grow and coalesce into visible macrocracks.

A great sum of damage models in different conditions have been proposed on the basis of damage mechanics and statistical principle. Yang et al. [39] explored a damage constitutive model of uniaxial load on Marble and discussed the physical and mechanical interpretation, which offered some important reference and insights into the damage model development. Krajcinovic and Fonseka [40] clearly defined the physical interpretation of the damage and proposed a rigorous mathematical description of the damage growth. The analytical model was applied to uniaxial tension, compression, and plane problems. This research made an important contribution, and a damage constitutive model was developed based on Weibull distribution, and the effect of model parameters on deformation characteristic after stress-temperature cycling was also discussed [41]. Fang et al. [42] established a model to predict deformation characteristics under freeze-thaw and loading cycles, which shows great achievement at predicting the deformation characteristics and peak strength of rock engineering materials. In statistical constitutive modelling [43], the maximum entropy distribution, instead of the conventional distribution law, was applied to describe the element strength, which is more suitable and flexible than Weibull distribution-based models. A previous study also reported a method to estimate the sizes of damage zones based on the thermal distribution, which provides an important direction for future model analytical work [44].

This paper has been divided into three parts. The first part establishes the experimental system containing both a loading section and a variety of testing equipment for the high-speed image acquisition section and acoustic emission signal acquisition section. The DIC method was applied to analyse these images and obtain stress and strain fields. The cooperation of these sections can provide sufficient proof to show the deformation and fracture of brittle rock. Then, a constitutive model was proposed. Based on the simplified characteristics of microcracks in sandstone, we present a microcrack damage model, proposing a constitutive model for brittle rock-like materials under tension that uses the Griffith strength criterion. After applying the basic parameters of the sandstone into the model, the verification of theoretical damage constitutive model by comparing the results of Brazilian disk tensile test should be added to fully introduce the work in this paper, and the results are discussed in the end.

\section{Indirect Tensile Test}

2.1. Sample Preparation and Mineralogy. Sandstone blocks were collected from an open pit mine in Inner Mongolia, China, at an altitude of 1600 MASL. Brazilian tensile samples without any through-cracks or weak planes were shaped into $\Phi 50 \times 25 \mathrm{~mm}$ disks [45] (Figure 1, top and back views). A grinding machine was used to further grind the surfaces to keep the parallelism error below $0.02 \mathrm{~mm}$. On the surface of each sample, evenly distributed spots were drawn on one flat surface (Figure 1, front view). Four samples (B-2, B-3, B-4 and B-5) were tested.

Uniaxial and triaxial experiments were conducted with a servo-controlled triaxial loading system to acquire the basic mechanical parameters, and Table 1 lists the mechanical properties of the rock sample. Table 2 lists the micromineral content measured by X-ray diffraction analysis.

2.2. Apparatus and Procedure. Testing was conducted using a servo-controlled loading apparatus comprising an axial loading device, electrohydraulic servo loading system, measurement control system, and computer control and data collection system (Figure 2). In the loading process, the load as well as deformation was simultaneously recorded by loading control and data collection system. The top surface of the upper plate is spherical with the same curvature as the nut (Figure 2). Thus, at the beginning of the test, a few seconds were required to centre and balance the upper plates and nut to avoid test deviation due to eccentric loading.

A high-speed (1000 frames/sec) camera (Figure 2) was placed in front of the sample's speckled surface, and it collected images showing the development of the deformation and fracture of the specimens with speckled surfaces, which could subsequently be analysed by means of DIC to show the deformation and strain field. To obtain clear spot images, daylight lamps were used on both sides of the specimens to obtain higher contrast images. Since the loading device and the high-speed camera were operated synchronously, the strain field of the sample and the stressstrain curve at every location could be output at the end of the test. Acoustic emission signal acquisition equipment has also been applied to detect the generation and development of cracks.

From the analysis results, it can be seen that the deformation of the disc was axially symmetrical. Therefore, one location on the $x$-axis (point A) was selected for analysis. On point $\mathrm{A}$, the stress parallel to the $x$-axis $\left(\sigma_{x}\right)$ and the strain parallel to the $x$-axis $\left(\varepsilon_{x}\right)$ were calculated.

\section{Construction of the Damage Model}

3.1. Microcrack Distribution Assumptions. To construct a damage model, the distribution parameters and fracture mechanical properties of a single microcrack must be defined. As noted above, the numerous microcracks in rocks follow statistical distribution, such as the uniform (Figure 3(a)) and Weibull distributions (Figure 3(b)).

To estimate the mechanical properties, all microcracks are composited using integral principle, assuming no external disturbance in the two-dimensional plane. The initial microcracks are the main cracks and wing cracks (Figure 4).

The statistical parameters of main cracks are density, length, and angle in the horizontal direction.

The main crack distribution function is [27]

$$
\varnothing(l, \beta)=\rho_{0} g(l) f(\beta),
$$



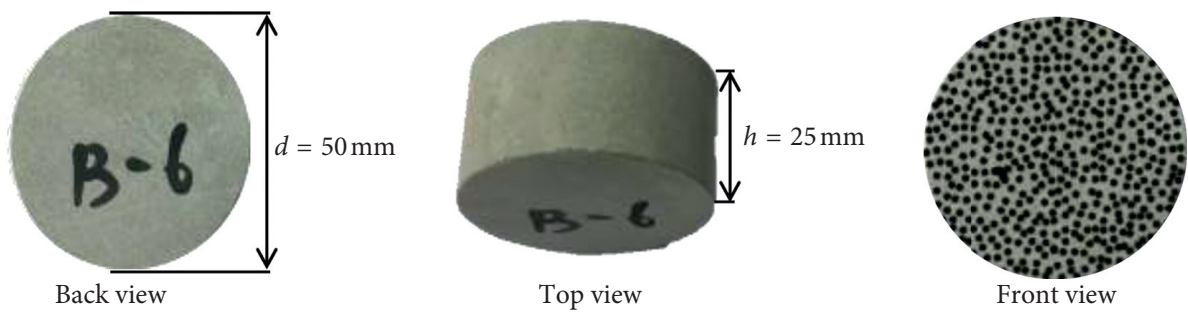

Figure 1: Specimens with nonvisible cracks and weak planes for Brazilian disks.

TABLE 1: Mechanical parameters of the rock samples.

\begin{tabular}{cccccc}
\hline Rock samples & $\rho\left(\mathrm{g} / \mathrm{cm}^{3}\right)$ & $\mathrm{E}(\mathrm{GPa})$ & $f_{c}(\mathrm{MPa})$ & $\nu$ & $\varphi\left(^{\circ}\right)$ \\
\hline 2.90 & 13.44 & 123.9 & 0.25 & 60.80
\end{tabular}

$\rho$ refers to the density, $E$ refers to the modulus of elasticity, $f_{c}$ refers to the uniaxial compressive strength, $v$ refers to the Poisson ratio, and $\varphi$ refers to the internal friction angle.

TABle 2: Microcomponents of the samples by X-ray diffraction analysis.

\begin{tabular}{|c|c|c|c|c|c|}
\hline \multirow[b]{2}{*}{ Quartz } & \multicolumn{4}{|c|}{ Mineral components and contents (\%) } & \multirow{2}{*}{$\begin{array}{c}\text { Clay } \\
\text { mineral } \\
\text { content }(\%)\end{array}$} \\
\hline & $\begin{array}{c}\text { K- } \\
\text { feldspar }\end{array}$ & Plagioclase & Calcspar & Dolomite & \\
\hline 24.0 & 6.3 & 43.1 & 5.7 & 2.2 & 18.7 \\
\hline
\end{tabular}

where $\rho_{0}$ refers to the density of microcracks $\left(\mathrm{m}^{-2}\right)$, which is a fixed parameter; $l$ is the half-length $(\mathrm{m})$, which is assumed to be micron-sized and follows the Weibull distribution; $f(\beta)$ is the density distribution of the crack angle $\beta$, shown in equation (2); and $g(l)$ is the density distribution function of the main crack length (equation (3)).

$$
f(\beta)=\delta\left(\beta-\beta_{0}\right),
$$

where $\delta$ is the distribution factor and $\beta_{0}$ is the angle from a known range of values for $\beta$.

$$
g(l)=\frac{m}{l}\left(\frac{l}{l_{0}}\right)^{m-1} \exp \left[-\left(\frac{l}{l_{0}}\right)^{m}\right]
$$

The scale parameter $l_{0}$ is set according to the original half-length of the microcrack. When the shape parameter $m$ is 2, it is also called the Rayleigh distribution:

$$
g(l)=\frac{2}{l_{0}} \exp \left[-\left(\frac{l}{l_{0}}\right)^{2}\right]
$$

3.2. Damage Constitutive Equation. The damage variable (D) is defined as

$$
D=\frac{N_{d}}{N}
$$

where $N_{d}$ is the number of microelements containing cracks originally and $N$ refers to the total amount of microelements.

The microelement stress level $\sigma$ follows the probability distributions, and the strength density of the microelement is described by the probability function $p$. The number of failures in the arbitrary interval of the stress level, $[\sigma, \sigma+\mathrm{d} \sigma]$, is

$$
\mathrm{d} N_{d}=N p(\sigma) \mathrm{d} \sigma .
$$

When the stress increases to a certain level $\sigma_{0}$, the destroyed microelement number is

$$
N_{d}=\int N P(x) \mathrm{d} x=N P\left(\sigma_{0}\right),
$$

where $P$ is the function of the microelement strength distribution. Equating (5) and (7) gives the general equation for the statistical damage evolution:

$$
D=P\left(\sigma_{0}\right) \text {. }
$$

For any kind of probability distribution, the distribution values vary from 0 to 1 , consistent with the change law of $D$. Different strength criteria can be applied to rule the stress level $\sigma$.

For a general element with a microcrack and an applied tensile load, the Griffith criterion in a planar state is

$$
\left\{\begin{array}{l}
\sigma_{1}+3 \sigma_{3}<0, \quad \sigma_{3}=-\sigma_{t} \\
\sigma_{1}+3 \sigma_{3}<0, \quad \frac{\left(\sigma_{1}-\sigma_{3}\right)^{2}}{\sigma_{1}+\sigma_{3}}=8 \sigma_{t}
\end{array}\right.
$$

where, $\sigma_{1,3}$ are the stresses on the element in the two main orthogonal directions. $\sigma_{t}$ is the tension strength.

Introducing the strain equivalence principle [46], the main strain $\varepsilon_{i}$ of the element can be obtained on the foundation of Hooke's law:

$$
\varepsilon_{i}=\frac{1}{E}\left[(1+v) \sigma_{i}^{*}-v \sum \sigma_{i}^{*}\right], \quad(i=1,3),
$$

where $E$ is the elastic modulus, $v$ is Poisson's ratio, and $\sigma_{i}^{*}$ is effective stress defined as follows:

$$
\sigma_{i}^{*}=\frac{\sigma_{i}}{1-D}
$$

Therefore, the statistical damage variable $D$ can be written as

$$
D=P\left(\sigma_{0}\right)=1-\frac{1}{E \varepsilon_{i}}\left[(1+v) \sigma_{i}-v \sum \sigma_{i}\right], \quad(i=1,3) .
$$

The effective elastic modulus can be defined as 


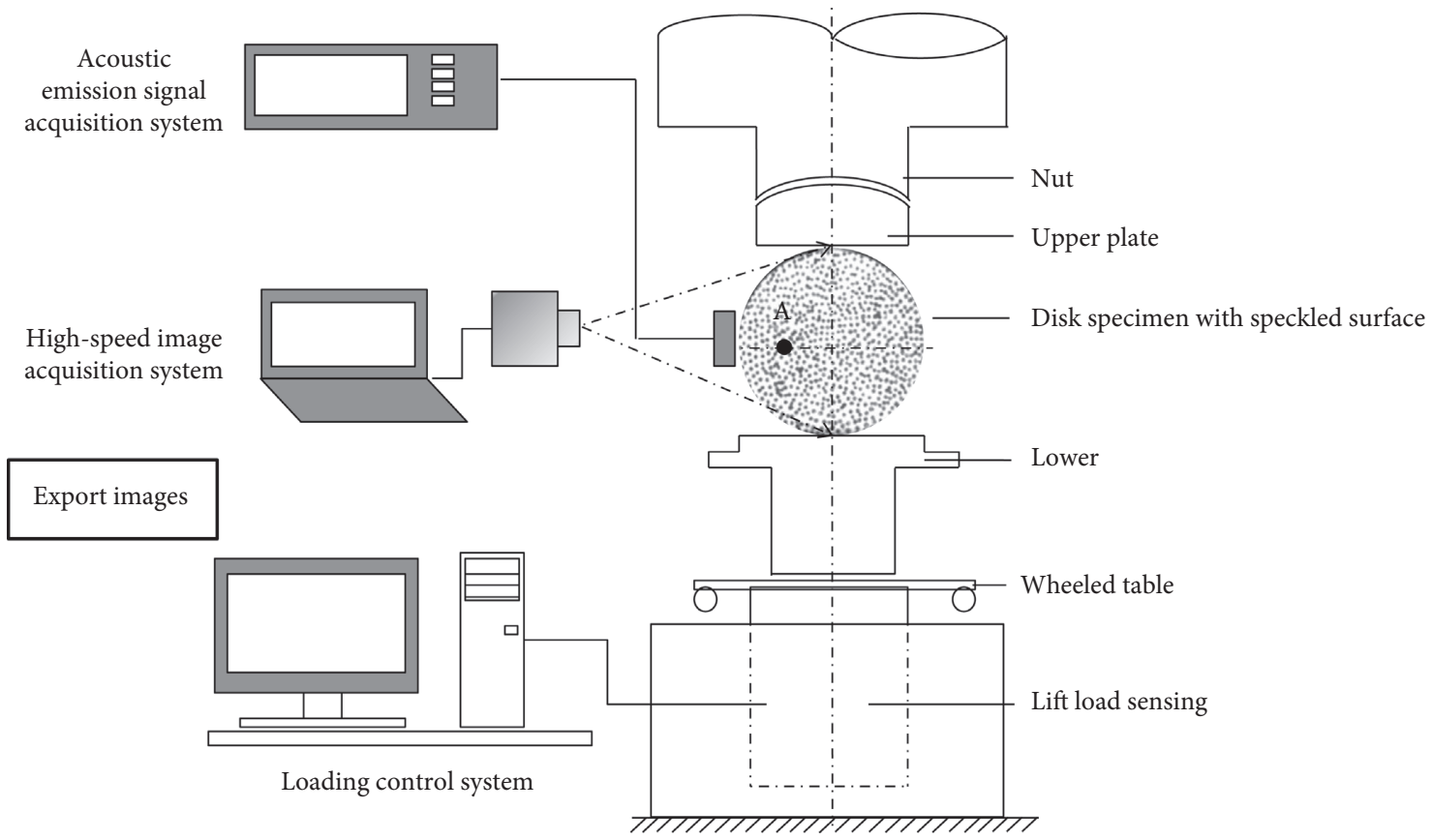

(a)
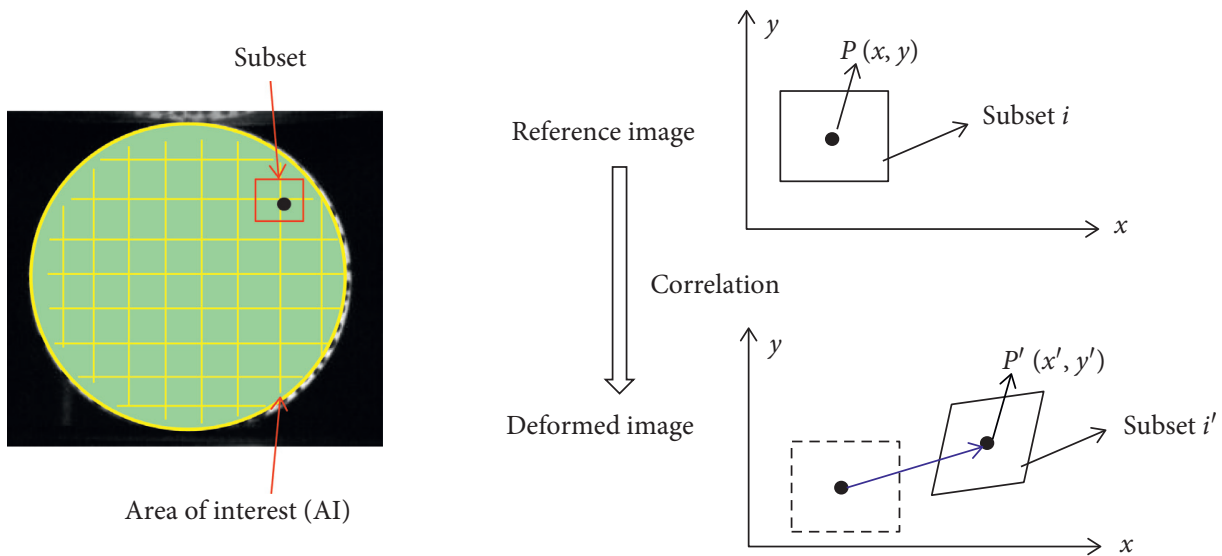

(b)

Figure 2: Schematic of (a) the Brazilian disk test experimental apparatus and the setup and (b) principle of DIC.

$$
E^{*}=\left[1-P\left(\sigma_{0}\right)\right] E \text {. }
$$

Based on Bernard's calculation method for the effective elastic parameters of a cracked solid [22], the elastic modulus is modified as follows:

$$
\frac{E^{*}}{E}=1-\frac{16\left(1-v^{* 2}\right)}{45}\left[3+T\left(f, v^{*}\right)\right] \xi,
$$

where $v^{*}$ is effective Poisson's ratio. We assume that Poisson's ratio with microcracks does not change during deformation and failure, that is, $\nu^{*}=\nu . T$ is a parameter related to the crack size and effective Poisson's ratio, and $\xi$ is a parameter related to the number of cracks.

According to Budiansky and O'Connell [22], for long, narrow elliptic cracks,

$$
\begin{aligned}
& T=\frac{2-v^{*}}{1-\nu^{*}}, \\
& \xi=\left(\frac{\pi}{2}\right) n,
\end{aligned}
$$

where $n$ is the number of microcracks per unit volume. The parameters $T, \xi$, and $D$ are substituted into equations (18a and $18 \mathrm{~b})$ :

$$
E^{*}=\left[1-\frac{8 \pi}{45}\left(1+v^{*}\right)\left(5-2 v^{*}\right) n\right] E .
$$

Combining equation (16) with equations (9) and (10), the damage statistical constitutive equation can be obtained. 


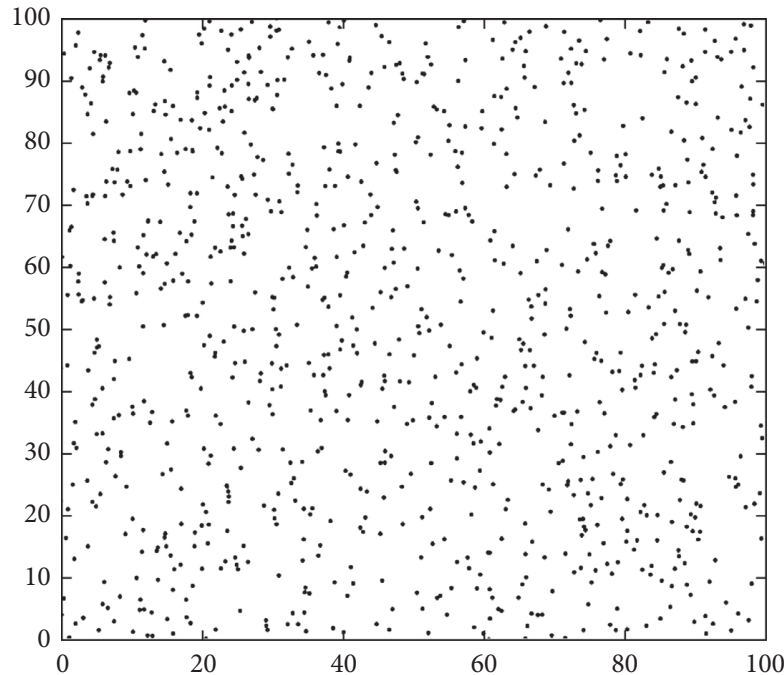

(a)

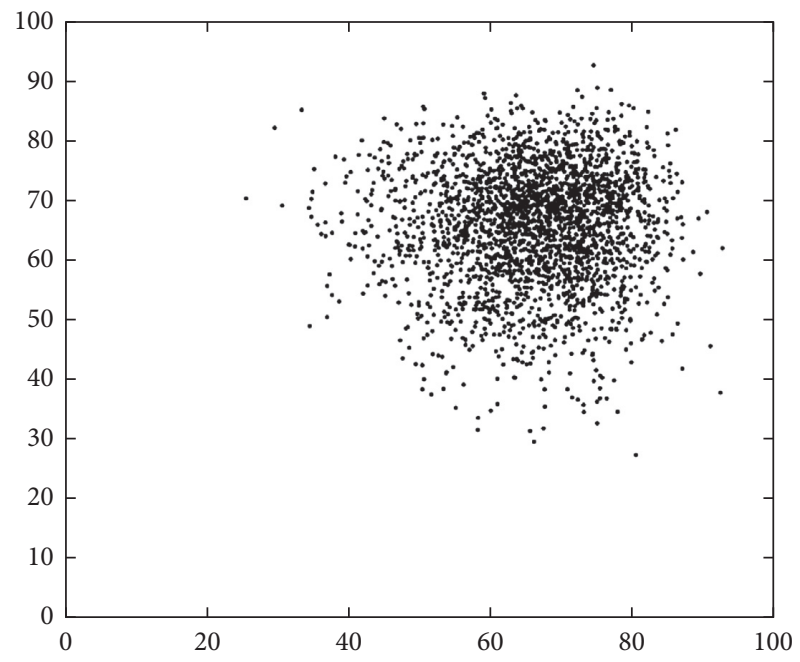

(b)

Figure 3: Two-dimensional diagrams of the (a) uniform and (b) Weibull distributions of microcracks inside a rock.

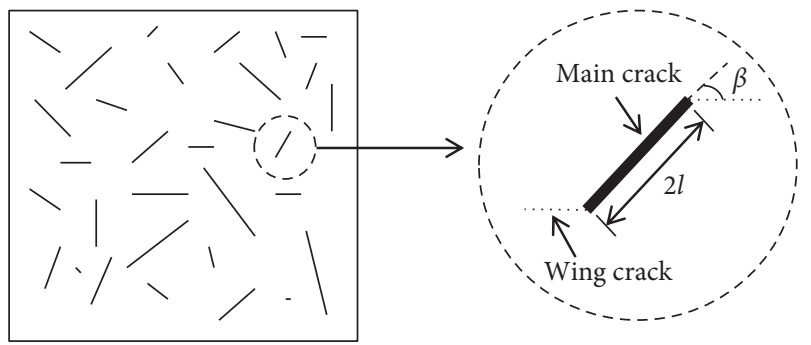

FIGURE 4: Statistical parameters of the main and wing microcracks in rocks. $l$ : the half-length; $\beta$ : angle between the direction of crack and horizontal direction.

3.3. Propagation of Cracks. It is assumed that the upper and lower sides of the rock sample are subjected to a uniform tension $q$. A penetration crack in the centre of the sample has a length of $2 l$, and the angle between the crack and the horizontal is $\beta$. During the calculation, the Cartesian system xoy uses the crack centre as the origin of the coordinate, and the polar coordinate system considers the crack tip as the origin. $r$ and $\theta$ are the variables in the polar coordinate system. The initial tension problem with cracks (Figure 5(a)) is converted into the sum of two parts: a 2-D plane element with a mode-I (open) crack in the centre that is stretched uniaxially in the $y$-direction (Figure $5(\mathrm{~b})$ ) and $x$-direction (Figure 5(c)); and an element containing a mode-II (slit) crack subjected to uniform shear (Figure 5(d)).

The equivalent boundary stresses are as follows:

$$
\left\{\begin{array}{l}
\sigma_{x}=q \cos ^{2} \beta, \\
\sigma_{y}=q \sin ^{2} \beta, \\
\tau_{x y}=q \sin \beta \cos \beta .
\end{array}\right.
$$

It has been verified [47] that for the mode-I crack issue, only the uniaxial tension in the $y$-direction (Figure 5(b)) needs to be considered, and the results of the uniform stress field on the effect of the force in the $x$-direction (Figure 5(c)) can be superimposed.

Based on the Westergaard function, $Z_{\mathrm{I}}(z)$ ( $\left.i=\mathrm{I}, \mathrm{II}\right)$, the general forms of the formula for the stress field at the tips of mode-I and mode-II cracks [47] are given as function equations (18a) and (18b), respectively.

$$
\begin{aligned}
& \left\{\begin{array}{l}
\sigma_{x x}=\operatorname{Re} Z_{\mathrm{I}}(z)-y \operatorname{Im} Z_{\mathrm{I}}^{\prime}(z), \\
\sigma_{y y}=\operatorname{Re} Z_{\mathrm{I}}(z)+y \operatorname{Im} Z_{\mathrm{I}}^{\prime}(z), \\
\tau_{x y}=-y \operatorname{Re} Z_{\mathrm{I}}^{\prime}(z),
\end{array}\right. \\
& \left\{\begin{array}{l}
\sigma_{x x}=y \operatorname{Re} Z_{\mathrm{II}}^{\prime}(z)+2 \operatorname{Im} Z_{\mathrm{II}}(z), \\
\sigma_{y y}=-y \operatorname{Re} Z_{\mathrm{II}}^{\prime}(z), \\
\tau_{x y}=\operatorname{Re} Z_{\mathrm{II}}(z)-y \operatorname{Im} Z_{\mathrm{II}}^{\prime}(z) .
\end{array}\right.
\end{aligned}
$$

The Westergaard function for the crack tip under uniaxial tension is

$$
Z_{I}(z)=\frac{\sigma z}{\sqrt{z^{2}-l^{2}}}-\frac{\sigma}{2}
$$

Substituting equation (18a) into the calculation, the stress field of mode-I crack-tip under uniaxial tension can be obtained:

$$
\begin{aligned}
& \sigma_{x x}=\frac{q \sin ^{2} \beta}{2}\left[\sqrt{\frac{l}{2 r}} \cos \frac{\theta}{2}(1+\cos \theta+r \sin \theta)-1\right], \\
& \sigma_{x x}=\frac{q \sin ^{2} \beta}{2}\left[\sqrt{\frac{l}{2 r}} \cos \frac{\theta}{2}(3-\cos \theta-r \sin \theta)-1\right], \\
& \sigma_{x x}=\frac{q \sin ^{2} \beta}{2} \sqrt{\frac{l}{2 r}} \sin \theta\left(\cos \frac{\theta}{2}+r \sin \frac{\theta}{2}\right) .
\end{aligned}
$$




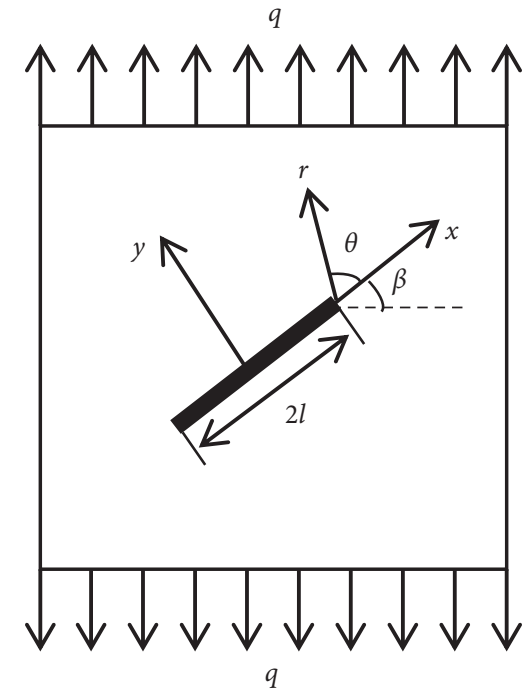

(a)

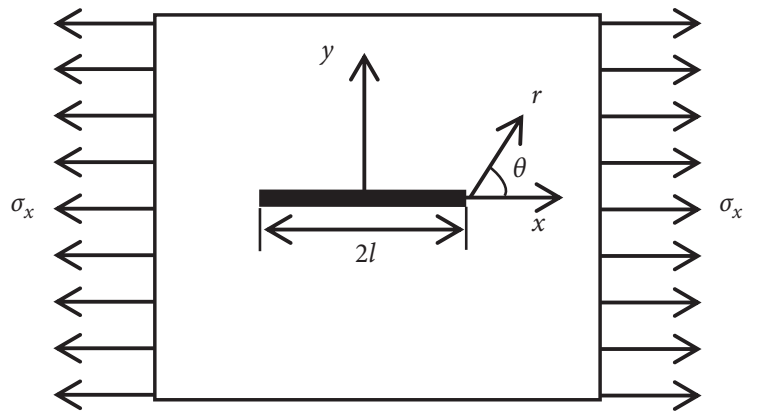

(c)

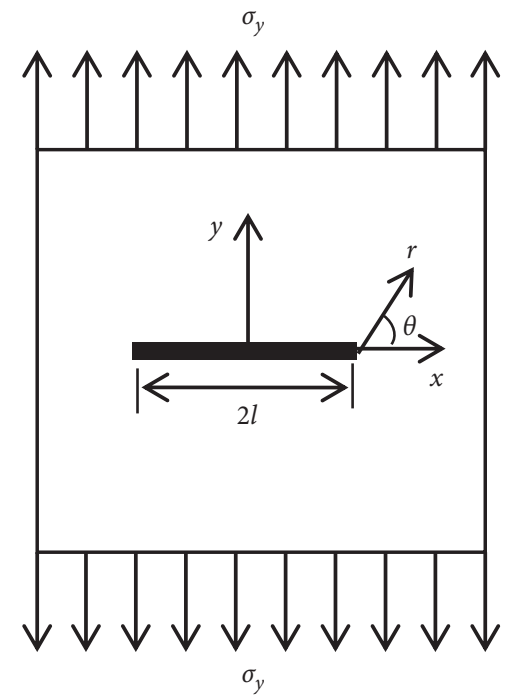

(b)

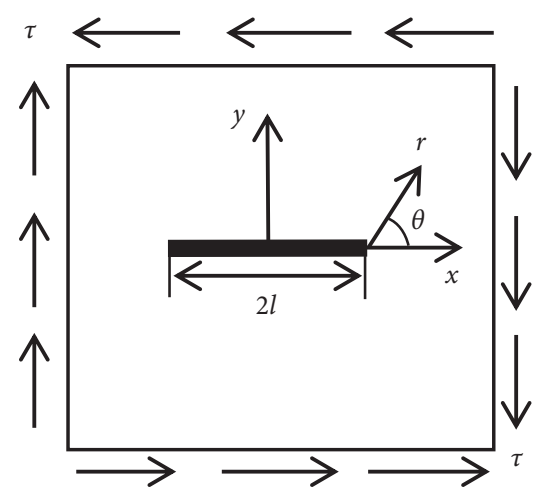

(d)

FIGURE 5: Calculation model of the crack propagation criterion: (a) initial tension problem with cracks; (b) a 2-D plane element with a mode-I (open) crack in the centre with uniaxial tension in the $y$-direction; (c) a 2-D plane element with mode-I crack in the centre with uniaxial tension in the $x$-direction; and (d) a 2-D plane element containing a mode-II (slit) crack subjected to uniform shear.

For mode-II cracks under a uniform shear force, the Westergaard function is:

$$
Z_{\mathrm{II}}(z)=\frac{\tau z}{\sqrt{z^{2}-l^{2}}}
$$

By substituting equation (18b), the stress field of mode-II crack-tip under uniform shear force can be obtained:

$$
\begin{aligned}
& \sigma_{x x}=-q \sin \beta \cos \beta \sqrt{\frac{2 l}{r}}\left(\sin \frac{\theta}{2}-\frac{1}{4} \sin \theta \cos \frac{3 \theta}{2}\right), \\
& \sigma_{y y}=q \sin \beta \cos \beta \sqrt{\frac{l}{2 r}} \frac{\sin \theta}{2} \cos \frac{3 \theta}{2}, \\
& \sigma_{x x}=q \sin \beta \cos \beta \sqrt{\frac{l}{2 r}}\left(\cos \frac{\theta}{2}-\frac{\sin \theta}{2} \sin \frac{3 \theta}{2}\right) .
\end{aligned}
$$

Thus, the modes I and II stress intensity factors under static loading are:

$$
\begin{aligned}
& K_{\mathrm{I}}=\lim _{r \longrightarrow 0}\left[\sigma_{y y(\theta=0)}\right] \cdot \sqrt{2 \pi r}=q \sqrt{\pi l}, \\
& K_{\mathrm{II}}=\lim _{r \longrightarrow 0}\left[\sigma_{x y(\theta=0)}\right] \cdot \sqrt{2 \pi r}=\tau \sqrt{\pi l} .
\end{aligned}
$$

When the load increases, the stress intensity factor meets the propagation criterion $K_{\mathrm{I}} \geq K_{\mathrm{I}} \mathrm{C}(i=\mathrm{I}, \mathrm{II})$, and the crack begins to expand.

\section{Results and Discussion}

According to the analytical solution for the problem of elastic mechanics on the plane stress, the stress state at point $T(x, y)$ in the disk specimen (Figure 6) is as follows: 

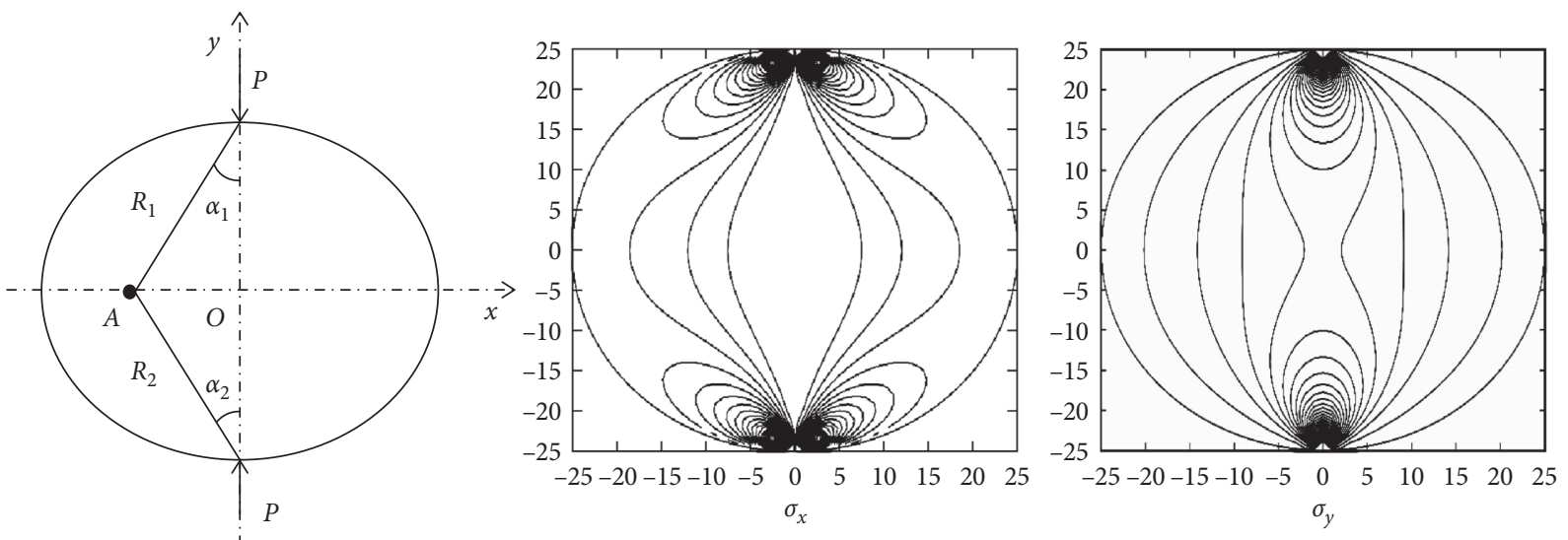

Figure 6: Stress analysis diagram of the Brazilian disc and the distribution of the stress analytic solution.

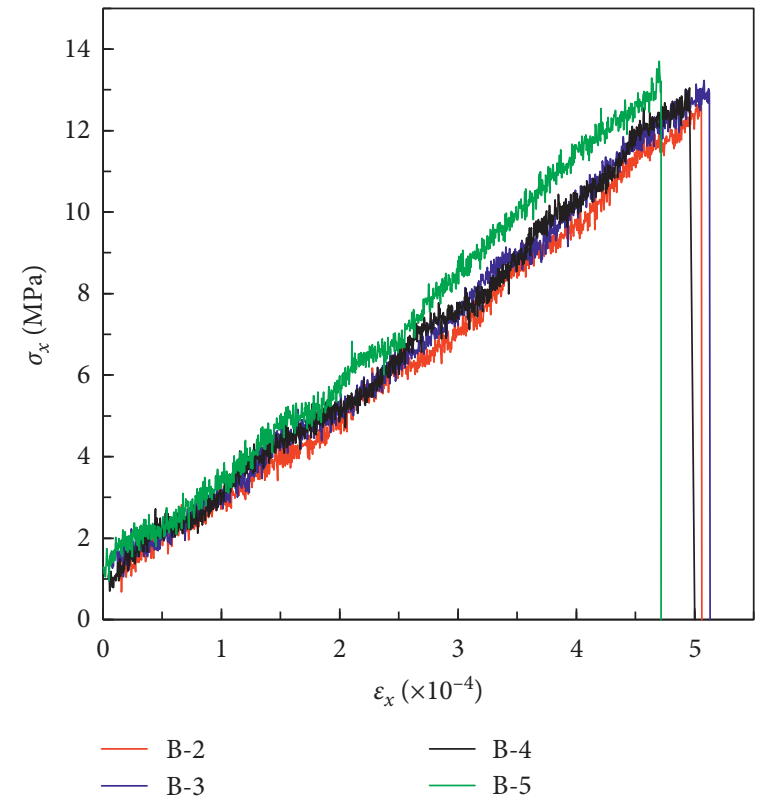

(a)

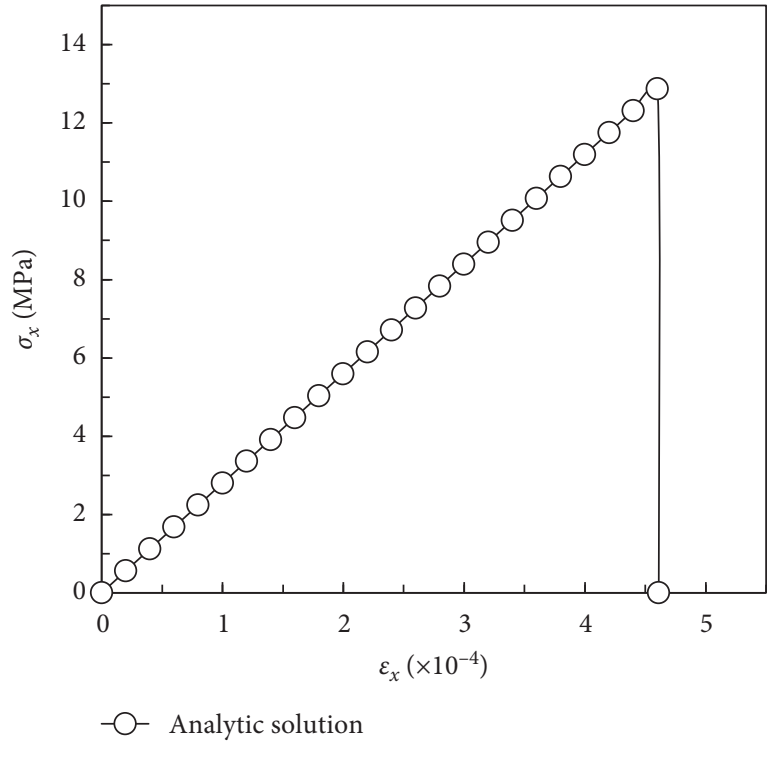

(b)

FiguRE 7: Measured (a) and modelled (b) stress-strain curves for four sandstone specimens.

$$
\begin{aligned}
& \sigma_{x}=\frac{2 P}{\pi h}\left[\frac{\sin ^{2} \alpha_{1} \cos \alpha_{1}}{R_{1}}+\frac{\sin ^{2} \alpha_{2} \cos \alpha_{2}}{R_{2}}\right]-\frac{2 P}{\pi d h}, \\
& \sigma_{y}=\frac{2 P}{\pi h}\left[\frac{\cos ^{3} \alpha_{1}}{R_{1}}+\frac{\cos ^{3} \alpha_{2}}{R_{2}}\right]-\frac{2 P}{\pi d h}, \\
& \tau_{x y}=\frac{2 P}{\pi h}\left[\frac{\sin \alpha_{1} \cos ^{2} \alpha_{1}}{R_{1}}-\frac{\sin \alpha_{2} \cos ^{2} \alpha_{2}}{R_{2}}\right] .
\end{aligned}
$$

The stress of point A, located on the centre line of the specimen perpendicular to the loading direction, is

$$
\sigma_{x}=\frac{2 P}{\pi d h}\left[\frac{16 d^{2} x^{2}}{\left(4 x^{2}+d^{2}\right)^{2}}-1\right] .
$$

By combining the stress with the full-field strain from the DIC analysis, stress-strain curves for the Brazilian tensile test were obtained (Figure 7). The Brazilian tensile test results at point A (Figure 6) on samples B-2 to B-5 showed that the maximum tensile stress $\left(\sigma_{x \max }\right)$ was approximately $13 \mathrm{MPa}$ and the maximum strain $\left(\varepsilon_{x \max }\right)$ was nearly $5 \times 10^{-4}$. Meanwhile, by applying the mechanical and assumed parameters in Table 1 to the statistical damage constitutive equation shown in Section 2.2, the expected model results for these sandstone samples were exported (shown in Figure 7). The stress-strain curve for the analytical model agreed well with the experimental data (Figure 7). Therefore, the model can describe the basic tensile properties of sandstone under tensile loading, namely, the tensile strength (maximum value in the stress-strain curves) and the modulus (slope in stress-strain curves). 


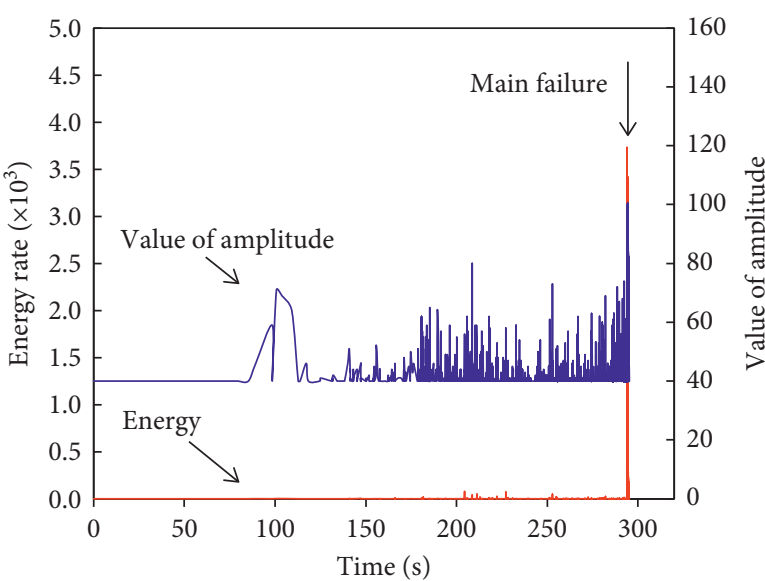

(a)

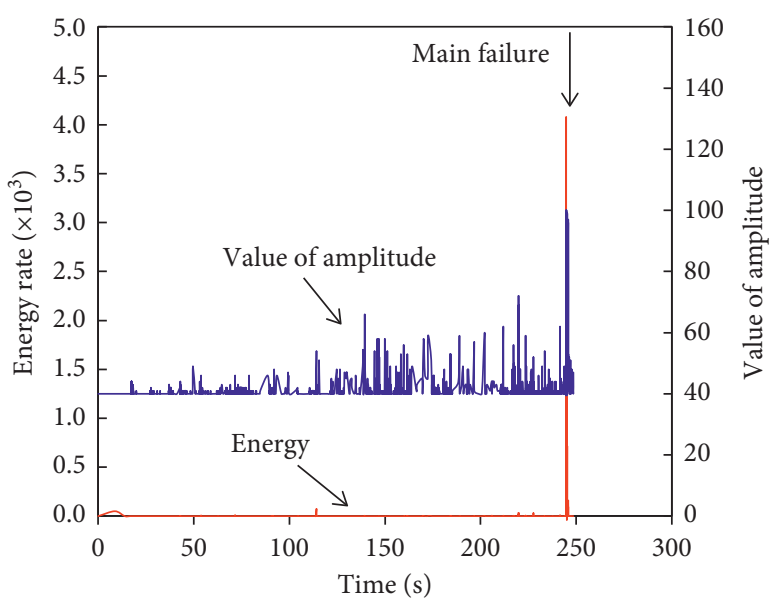

(c)

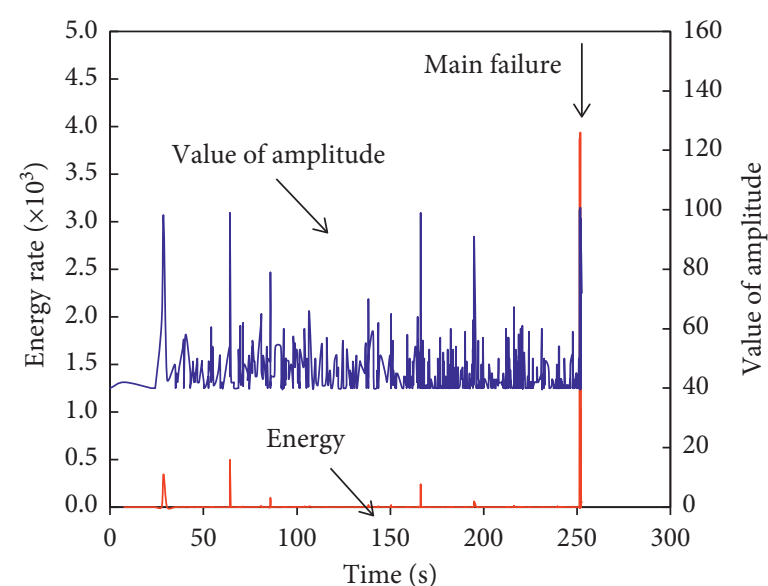

(b)

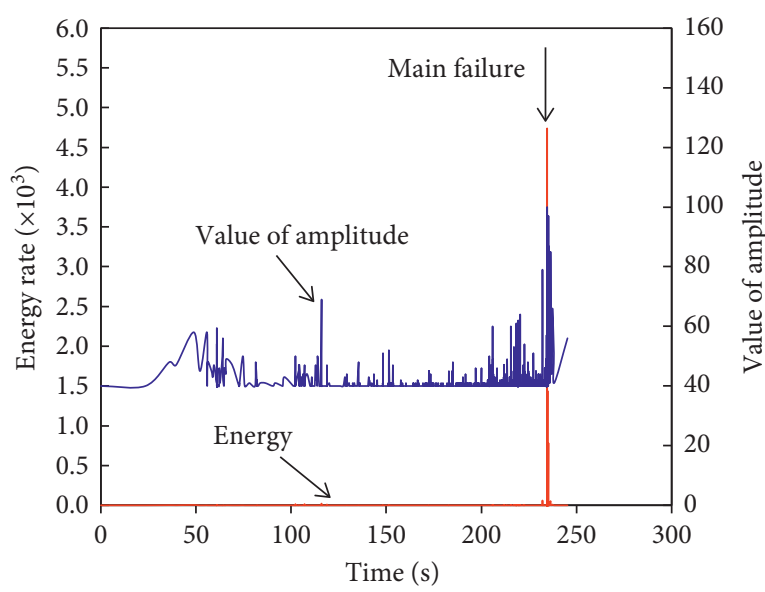

(d)

FIGURE 8: Acoustic emission characteristics and strain field of AI before the samples were broken and analysed by DIC. (a) B-2. (b) B-3. (c) B-4. (d) B-5.

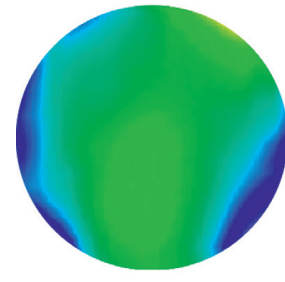

$4.5 \mathrm{kN}$

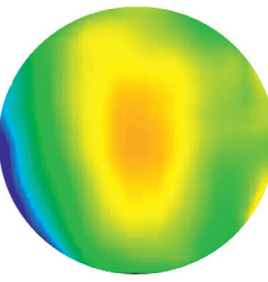

$10 \mathrm{kN}$

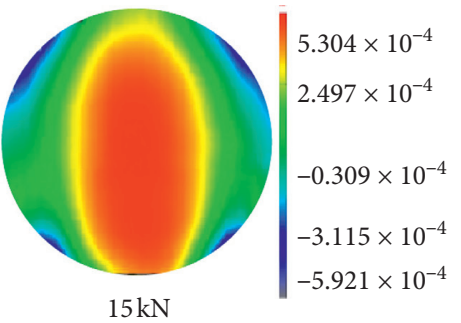

$15 \mathrm{kN}$

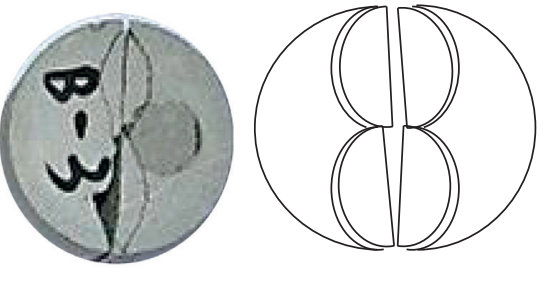

Fracture mode

Figure 9: The evolution of the tensile strain $\varepsilon_{x x}$ fracture mode (taking sample B-3 as an example) at different loading stages (4.5 MPa, $10 \mathrm{MPa}$, and $15 \mathrm{MPa}$ ).

Before the main fracture occurred, there was no visible crack on the surface, and the specimens did not show obvious deformation. The results from the acoustic emission events were applied to detect the development of damage in the rock. As shown in Figure 8, before the main fracture, there were $\mathrm{AE}$ events with different degrees of amplitude, which indicated that cracks were generated and developed. Although there were several peaks of acoustic emissions during the loading process, the energy released was negligibly small. For most specimens, the frequency of the acoustic emission increases near the main rupture. The energy rate and value of the amplitude reached the peak at the moment of the main fracture.

The DIC method was applied to analyse images captured by a high-speed image acquisition system, and full-field displacements and the strain of the samples were extracted from those recording images containing measurement data. Taking specimen B-3 as an example, the evolution of the 
tensile strain field and typical fracture mode is shown in Figure 9.

In the loading stage, the macroscopic crack on the surface of the specimen will be accompanied by the fracture failure of the specimens. Due to the performance of the camera, it is difficult to capture the propagation process of the large crack and the damage surface. For most specimens, the horizontal strain $\varepsilon_{x x}$, which is also considered a tensile strain, is symmetric along the axis of the loading centre line. The maximum deformation region and the fracture surface are also on the loading centre line.

\section{Conclusions}

To investigate the deformation internal damage of brittle rock, this study applied Brazilian tensile laboratory tests carried out by a servo-controlled loading apparatus on sandstone. The acoustic emission signal acquisition system and the high-speed image acquisition system are applied in the process of the Brazilian tensile test. The results from this work highlight the relationships among the damage development, acoustic emission, and DIC analysis results.

The general statistical damage constitutive model for brittle rock under tension is deduced. The microcrack distribution obeyed the statistical law: the crack distribution function was represented by the distribution function of the inclination angle and the half-length. According to Griffith strength criterion, the microstress level defines the statistical damage variable and then derives the effective elastic constant and the constitutive equation in the tensile state.

The Brazilian tensile test results were in good agreement with the theoretical stress-strain curve. The established microcrack damage constitutive model can predict the mechanical properties of brittle rock-like materials under tension with reasonable parameters and assumptions.

\section{Data Availability}

The data used to support the findings of this study are included within the article.

\section{Conflicts of Interest}

The authors declare that they have no conflicts of interest.

\section{Acknowledgments}

This work was funded by the project (ZR2017PD011) and supported by the Natural Science Foundation of Shandong Province. The authors gratefully acknowledge this support.

\section{References}

[1] S. F. Li and G. Wang, Introduction to Micromechanics and Nanomechanics, World Scientific Publishing Company, Singapore, 2nd edition, 2008.

[2] G. Shi, X. Yang, H. Yu, and C. Zhu, "Acoustic emission characteristics of creep fracture evolution in double-fracture fine sandstone under uniaxial compression," Engineering Fracture Mechanics, vol. 210, pp. 13-28, 2019.
[3] C. Zhu, Z. Tao, S. Yang, and S. Zhao, "V shaped gully method for controlling rockfall on high-steep slopes in China," Bulletin of Engineering Geology and the Environment, vol. 78, no. 1, pp. 2731-2747, 2019.

[4] H. X. Zhang, X. Y. Yin, and Z. Y. Zong, "Rock moduli estimation of inhomogeneous two-phase media with finite difference modeling algorithm," Journal of Geophysics and Engineering, vol. 15, no. 4, pp. 1517-1527, 2018.

[5] X. Yin, Y. Zheng, and Z. Zong, "Research on the equivalence between digital core and rock physics models," Journal of Geophysics and Engineering, vol. 14, no. 3, pp. 666-674, 2017.

[6] W. Jiang, J. Deng, and Y. Li, "Study on constitutive model of rock damage based on lognormal distribution," Chinese Journal of Underground Space and Engineering, vol. 6, pp. 1190-1194, 2010.

[7] L. Jean, "A continuous damage mechanics model for ductile fracture," Journal of Engineering Materials and Technology, vol. 107, pp. 83-89, 1985.

[8] B. Chen, S. Zhang, Y. Li, Z. Li, and H. Zhou, "Physical simulation study of crack propagation and instability information discrimination of rock-like materials with faults," Arabian Journal of Geosciences, vol. 13, 2020.

[9] J. Wang, Y. Zhang, Z. Qin, S. Song, and P. Lin, "Analysis method of water inrush for tunnels with damaged waterresisting rock mass based on finite element method-smooth particle hydrodynamics coupling," Computers and Geotechnics, vol. 126, 2020.

[10] Z. Li, F. Cheng, Y. Wei et al., "Study on coal damage evolution and surface stress field based on infrared radiation temperature," Journal of Geophysics and Engineering, vol. 15, no. 5, pp. 1889-1899, 2018.

[11] L. Li, S. Yan, Q. Liu, and L. Yu, "Micro- and macroscopic study of crack propagation in coal: theoretical and experimental results and engineering practice," Journal of Geophysics and Engineering, vol. 15, no. 4, pp. 1706-1718, 2018.

[12] B. Kong, Z. H. Li, and E. Y. Wang, "Fine characterization rock thermal damage by acoustic emission technique," Journal of Geophysics and Engineering, vol. 15, no. 1, pp. 10-12, 2018.

[13] D. Chen, E.-y. Wang, and N. Li, "Analyzing the rules of fracture and damage, and the characteristics of the acoustic emission signal of a gypsum specimen under uniaxial loading," Journal of Geophysics and Engineering, vol. 14, no. 4, pp. 780-791, 2017.

[14] H. Pan, D. Yin, N. Jiang, and Z. Xia, "Crack initiation behaviors of granite specimens containing crossing-doubleflaws with different lengths under uniaxial loading," Advances in Civil Engineering, vol. 2020, Article ID 8871335, 13 pages, 2020.

[15] D. Liu, Z. Gu, R. Liang et al., "Impacts of pore-throat system on fractal characterization of tight sandstones," Geofluids, vol. 2020, Article ID 4941501, 17 pages, 2020.

[16] G. Feng, X. Wang, M. Wang, and Y. Kang, "Experimental investigation of thermal cycling effect on fracture characteristics of granite in a geothermal-energy reservoir," Engineering Fracture Mechanics, vol. 235, 2020.

[17] J. Chen, J. Zhao, S. Zhang, Y. Zhang, F. Yang, and M. Li, “An experimental and analytical research on the evolution of mining cracks in deep floor rock mass," Pure and Applied Geophysics, vol. 2020, 16 pages, 2020.

[18] X. S. Liu, J. G. Ning, Y. L. Tan, and Q. H. Gu, "Damage constitutive model based on energy dissipation for intact rock subjected to cyclic loading," International Journal of Rock Mechanics and Mining Sciences, vol. 85, pp. 27-32, 2016. 
[19] X. S. Liu, Y. L. Tan, J. G. Ning, Y. W. Lu, and Q. H. Gu, "Mechanical properties and damage constitutive model of coal in coal-rock combined body," International Journal of Rock Mechanics and Mining Sciences, vol. 110, pp. 140-150, 2018.

[20] X. Wang, C. Liu, S. Chen, L. Chen, K. Li, and N. Liu, "Impact of coal sector's de-capacity policy on coal price," Applied Energy, vol. 265, pp. 5179-5192, Article ID 114802, 2020.

[21] F. Wu, J. Chen, and Q. Zou, "A nonlinear creep damage model for salt rock," International Journal of Damage Mechanics, vol. 28, no. 5, pp. 758-771, 2019.

[22] B. Budiansky and R. J. O’Connell, "Elastic moduli of a cracked solid," International Journal of Solids and Structures, vol. 12, no. 2, pp. 81-97, 1976.

[23] F. Carvalho, C. N. Chen, and J. F. Labuz, "Measurements of effective elastic modulus and microcrack density," International Journal of Rock Mechanics and Mining Sciences, vol. 34, no. 3-4, pp. 43.e1-43.e11, 1997.

[24] X. Q. Feng and S. W. Yu, "A simplified calculation method for effective moduli of micsocracked solids," Chinese Journal of Theoretical and Applied Mechanics, vol. 33, pp. 102-108, 2001.

[25] H. Horii and S. Nemat-Nasser, "Elastic fields of interacting inhomogeneities," International Journal of Solids and Structures, vol. 21, no. 7, pp. 731-745, 1985.

[26] X. Xing, "The foundation of nonequilibrium statistical fracture mechanics," Advance in Mechanics, vol. 21, pp. 153-168, 1991.

[27] J. W. Zhou and W. Y. Xu, "Investigation on the micro-crack damage model of brittle rock under uniaxial tensile loading," Chinese Journal of Solid Mechanics, vol. 30, pp. 509-514, 2009.

[28] K. Chen, M. Tang, and Z. Guo, "Comparative study on threedimensional conventional and modified statistical damage constitutive models," Multiscale and Multidisciplinary Modeling, Experiments and Design, vol. 2, no. 4, pp. 259-267, 2019.

[29] Y. Chen, L. Zhang, H. Xie, J. Liu, H. Liu, and B. Yang, "Damage ratio based on statistical damage constitutive model for rock," Mathematical Problems in Engineering, vol. 2019, pp. 1-12, 2019.

[30] P. Shen, H. Tang, D. Wang, Y. Ning, Y. Zhang, and X. Su, “A statistical damage constitutive model based on unified strength theory for embankment rocks," Marine Georesources \& Geotechnology, vol. 38, no. 7, pp. 818-829, 2019.

[31] X. Chen, P. He, Z. Qin, J. Li, and Y. Gong, "Statistical damage model of altered granite under dry-wet cycles," Symmetry, vol. 11, pp. 1-12, 2019.

[32] S. Li, J. Xu, Y. Tao, and X. Tang, "Study on damages constitutive model of rocks based on lognormal distribution," Journal of Coal Science \& Engineering (China), vol. 13, pp. 430-433, 2007.

[33] W. G. Cao, Z. L. Fang, and X. J. Tang, "A study of statistical constitutive model for soft and damage rocks," Chinese Journal of Rock Mechanics and Engineering, vol. 17, pp. 628-633, 1998.

[34] Y. Lin, K. Zhou, R. Gao, J. Li, and J. Zhang, "Influence of chemical corrosion on pore structure and mechanical properties of sandstone," Geofluids, vol. 2019, Article ID 7320536, 15 pages, 2019.

[35] Z.-l. Wang, Y.-c. Li, and J. G. Wang, "A damage-softening statistical constitutive model considering rock residual strength," Computers \& Geosciences, vol. 33, no. 1, pp. 1-9, 2007.

[36] L. Zhu, X. Xu, X. Cao, and S. Chen, "Statistical constitutive model of thermal damage for deep rock considering initial compaction stage and residual strength," Mathematical
Problems in Engineering, vol. 2019, Article ID 9035396, 10 pages, 2019.

[37] X. Xu, F. Gao, and Z. Zhang, "Thermo-mechanical coupling damage constitutive model of rock based on the Hoek-Brown strength criterion," International Journal of Damage Mechanics, vol. 27, no. 8, pp. 1213-1230, 2017.

[38] Z. Y. Tian, W. Wang, X. H. Li, and W. Y. Xu, "A statistical damage constitutive model for brittle rocks based on the ladeduncan failure criterion," Advanced Materials Research, vol. 919-921, pp. 632-636, 2014.

[39] S. Q. Yang, W. Y. Xu, and L. D. Wei, "Statistical constitutive model for rock damage under uniaxial compression and its experimental study," Journal of Hohai University (Natural Science), vol. 32, pp. 200-203, 2004.

[40] D. Krajcinovic and G. U. Fonseka, "The continuous damage theory of brittle materials, part 1: general theory," Journal of Applied Mechanics, vol. 48, no. 4, pp. 809-815, 1981.

[41] S.-W. Zhou, C.-C. Xia, H.-B. Zhao, S.-H. Mei, and Y. Zhou, "Statistical damage constitutive model for rocks subjected to cyclic stress and cyclic temperature," Acta Geophysica, vol. 65, no. 5, pp. 893-906, 2017.

[42] W. Fang, N. Jiang, and X. Luo, "Establishment of damage statistical constitutive model of loaded rock and method for determining its parameters under freeze-thaw condition," Cold Regions Science and Technology, vol. 160, pp. 31-38, 2019.

[43] J. Deng and D. Gu, "On a statistical damage constitutive model for rock materials," Computers \& Geosciences, vol. 37, no. 2, pp. 122-128, 2011.

[44] Q. Liu, Q. Liu, Y. Pan, X. Peng, P. Deng, and K. Huang, "Experimental study on rock indentation using infrared thermography and acoustic emission techniques," Journal of Geophysics and Engineering, vol. 15, no. 5, pp. 1864-1877, 2018.

[45] Z. T. Bieniawski and I. Hawkes, "Suggested methods for determining tensile strength of rock materials," in The Complete ISRM Suggested Methods for Rock Characterization, Testing and Monitoring: 1974-2006, U. Resat and H. John A, Eds., pp. 99-103, Compilation Arranged by the ISRM Turkish National Group, Ankara, Turkey, 1978.

[46] L. Jean, A Course on Damage Mechanics, Springer, Berlin, Germany, 2nd edition, 1992.

[47] S. Y. Li, T. M. HE, and X. C. Yi, Fracture Mechanics of Rock, Science Press, Beijing, China, 1st edition, 2015. 